\title{
Lactation Skills Workshop: A Collaboration of the City of Dallas WIC and Local Hospitals
}

\author{
Janice Ballou, DNP, PPCNP-BC, IBCLC ${ }^{1}$; Christine Wiseman, RN, IBCLC ${ }^{2}$; \\ Linda Jackson, MA, LCCE ${ }^{3}$; Reba Godfrey, RNC-MNN, IBCLC, LCCE ${ }^{4}$; \\ Dani Cagle, MPH, IBCLC ${ }^{5}$
}

\begin{abstract}
The Baby-Friendly Hospital Initiative, a global endeavor of the World Health Organization and the United Nations Children's Fund, is an evidence-based program identifying 10 interventions that when hospitals implement them, breastfeeding $(\mathrm{BF})$ rates improve. It recognizes the powerful role that health care workers have in successful BF and the need for competent hands-on skills to support lactation. The City of Dallas, TX, Special Supplemental Nutrition Program for Women, Infants, and Children (WIC) program collaborated with 3 urban hospitals and developed a training of practical techniques and information for staff to use while working with BF patients. Since implementation, 1,600 workers were trained, 1 hospital achieved Baby-Friendly designation, and all have increased BF rates by $10 \%$.

Key Words: WIC, Baby-Friendly, breastfeeding, collaboration, skills training (J Nutr Educ Behav. 2017;49:S202-S206.)
\end{abstract}

Accepted May 10, 2017.

\section{INTRODUCTION}

Breastfeeding (BF) has significant health benefits for infants and mothers. Infants who are breastfed have decreased incidence of asthma, allergies, and infections and a decreased likelihood of obesity and diabetes. ${ }^{1-3}$ Breast milk as well as the process of BF positively affects a baby's neurodevelopment. ${ }^{4}$ For mothers, there is a decrease in postpartum hemorrhage, diabetes, breast cancer, and uterine cancer. ${ }^{5,6}$ Both the American Academy of Pediatrics and the American Congress of Obstetricians and Gynecologists agreed that breast milk and BF should be the standard feeding choice for mothers and babies. ${ }^{7}$ The World Health Organization (WHO) and the US Centers for
Disease Control and Prevention recognized $\mathrm{BF}$ as a public health issue. ${ }^{8}$ If $90 \%$ of families followed the Healthy People 2020 BF recommendations, it is estimated that $\$ 13$ billion/year could be saved in medical and related costs. ${ }^{9}$

The Baby-Friendly Hospital Initiative (BFHI) is an evidenced-based program created by WHO and the United $\mathrm{Na}$ tions Children's Fund (UNICEF) to promote BF worldwide; in the US, it is administered by Baby-Friendly USA. ${ }^{10}$ The BFHI recognizes the powerful role of hospitals and health care workers in initiating successful BF practices. The WHO/UNICEF identified 10 steps that increase not only the number of women who choose to breastfeed but the duration of BF when they are im-

\footnotetext{
${ }^{1}$ Parkland Health and Hospital System, Dallas, TX

${ }^{2}$ City of Dallas Special Supplemental Nutrition Program for Women, Infants, and Children, Lactation Care Center, Dallas, TX

${ }^{3}$ Methodist Richardson Medical Center, Richardson, TX

${ }^{4}$ Methodist Charlton Medical Center, Dallas, TX

${ }^{5}$ Methodist Dallas Medical Center, Dallas, TX

Conflict of Interest Disclosure: The authors' conflict of interest disclosures can be found online with this article on www.jneb.org.

Address for correspondence: Janice Ballou, DNP, PPCNP-BC, IBCLC, Parkland Health and Hospital System, WISH, 3735 Ridgeoak Way, Farmers Branch, TX 75244; Phone: (214) 707-8563; E-mail: janiceballou57@gmail.com

(C)2017 Society for Nutrition Education and Behavior. Published by Elsevier, Inc. All rights reserved.
}

http://dx.doi.org/10.1016/j.jneb.2017.05.347 plemented (Table 1$).{ }^{11}$ When a hospital implements all 10 steps, it may be eligible for the Baby-Friendly designation, as determined by the Baby-Friendly USA surveyors. The pathway to the Baby-Friendly Hospital designation can be challenging, especially for hospitals for which medical resources are strained. $^{12}$

Three such hospitals in Dallas, TX, that serve racially and culturally diverse populations were in various stages of the Baby-Friendly journey: Methodist Dallas Medical Center, Methodist Charlton Medical Center, and Parkland Health and Hospital System. Parkland is a not for-profit public hospital with a mandate to furnish medical care to indigent and needy persons of Dallas County. The hospital receives funding through county taxes, charitable contributions, and patient payments. Many patients are nonfunded or have government-supported health insurance. Methodist Dallas Medical Center and Charlton are a part of the larger Methodist Health System in North Texas and are affiliated by covenant with the North Texas Conference of the United Methodist Church. The Methodist Health System is also not for profit and $10 \%$ of the care delivered is unreimbursed charity. Many of the patients from these facilities are served by the City of Dallas Special Supplemental Nutrition Program for Women, Infants, and Children (WIC) 
Table 1. World Health Organization/United Nations Children's Fund: 10 Steps to Successful Breastfeeding (BF) ${ }^{11}$

Every facility providing maternity services and care for newborn infants should:

1. Maintain a written BF policy that is regularly communicated to all health care workers

2. Train all health care staff in skills necessary to implement this policy

3. Inform all pregnant women about the benefits and management of BF

4. Help mothers initiate BF within $1 \mathrm{~h}$ of birth

5. Show mothers how to breastfeed and maintain lactation, even if separated from their infant

6. Give infants no food or drink other than breast milk, unless medically indicated

7. Practice rooming in together $24 \mathrm{~h} / \mathrm{d}$

8. Encourage unrestricted BF

9. Give no pacifiers or artificial nipples to BF infants

10. Foster establishment of BF support groups and refer mothers to them on discharge from the hospital or clinic

program. Over the past 15 years the WIC program created strong relationships with these hospitals to supplement the care provided to meet the nutritional needs of families.

The WIC BF peer counselors are available prenatally and postnatally to provide nutrition and BF education. They go into both the clinics and the hospitals to give mothers hands-on BF assistance. While the peer counselors are there, they facilitate follow-up in WIC clinics and provide information about other WIC programs. The WIC employees serve on several hospital-based BF committees and add insight into meeting the needs of families in and outside the hospital setting. These partnerships are invaluable in promoting and protecting BF in the community.

All of these hospitals are major teaching facilities for local nursing and medical schools. The University of Texas Southwest Medical School has a presence in Parkland with medical students and obstetric, pediatric, and family practice residents. The Methodist Health System has obstetric and family practice residents as well as an externship program for fourth-year medical students interested in family practice. The City of Dallas WIC developed several educational opportunities to augment various health care providers' training. Pediatric and family practice residents and nursing students spend time shadowing lactation consultants in the hospital and/or at the City of Dallas WIC Lactation Care Center (LCC). This opportunity is also available to newly hired nurses and nurse practitioners during their hospital orientation days. At the LCC, health care providers participate in didactic education, hands-on skills training, and direct observation of lactation consultations. In addition to the practical knowledge gained, these health care providers have the opportunity to see the care their patients receive after they are discharged from the hospital, and the patients have the occasion to give feedback to staff about their hospital experience.

The City of Dallas WIC wanted to expand their presence in hospital staff education to assist hospitals with the requirements of step 2 of the BFHI (Table 1). To meet this need, the manager of the City of Dallas WIC LCC approached the 3 hospitals about collaborating to develop a skills training workshop.

\section{Description of the Collaboration}

Step 2 focuses on educating the nursing staff and medical providers. This step specifies that physicians with privileges in maternity and nursery units have a minimum of 3 hours of BF education. There is wide latitude in the type and format of the educational offering required. Nurses with direct responsibility for teaching and caring for mothers and newborns have a 20-hour educational requirement. ${ }^{13}$ Fifteen of these hours are didactic and the clinical experience is an additional 5 hours. Many hospi- tals choose an online format for the 15 hours; however, it is more challenging to achieve to the 5 hours of clinical experience because they must be done under supervision and competency must be verified. This requirement may create a barrier to achieving BabyFriendly status because of the additional staff needed. The goals of the new collaboration with WIC were to provide staff a supervised clinical experience in a workshop format and provide a venue to practice the information they gained from the didactic education. A group of clinicians from the hospitals and the WIC program met to create such a workshop.

\section{Creation of Content}

The clinicians involved were the lactation consultant supervisors from the hospitals, a pediatric nurse practitioner, a registered dietitian, a WIC lactation consultant, and the manager of the City of Dallas WIC LCC. In addition, the creators of the workshop were certified lactation consultants through the International Board of Lactation Consultant and Examiners. The members of the committee wanted the content areas to correspond to the hands-on nursing skills identified in the 10 Steps and for the information to be relevant to participants. Therefore, each was tasked with polling the staff at their institutions about the areas in which they felt they needed the most help to assist appropriately with BF.

The members then selected 6 content areas for inclusion in the workshop and developed 20-minute modules based on current research and health care literature. The modules were: safe skin-toskin care, hand expression of breast milk, care and use of breast pumps, evaluation of an effective latch, supplemental feedings, and positive messaging. Table 2 outlines the learner objectives, instructional strategies, and equipment used to teach each module. The safe skin-to-skin care module presented evidence regarding the importance of skin-to-skin contact on an infant's transition to extrauterine life $\mathrm{e}^{14,15}$ as well as the phenomenon of sudden unexpected postnatal collapse. ${ }^{16}$ The hand expression module incorporated research by Dr Jane Morton and colleagues from the Stanford School 
Table 2. Six Content Areas for Lactation Workshop Modules

\section{Module}

Safe skin-to-skin To identify the effects of SSC on: contact (SSC)

Hand expression of breast milk

\section{Care and use of breast pumps}

Evaluation of an effective latch

\section{Use of supplemental feedings}

Positive messaging
- physiologic stabilization after birth,

- infant neurodevelopment, and

- initiation and success of BF

To demonstrate:

- proper positioning for SSC

To define:

- sudden unexpected postnatal collapse $^{a}$

To identify:

- effective hand expression techniques,

- at least 3 benefits of hand expression, and

- at least 3 advantages of simultaneous hand expression \& pumping

- how to make a hands-free pumping bra from a sports bra

To identify:

- indications for use of a manual versus an electric breast pump,

- properly fitting pump flanges for breast size,

- correct set up and cleaning of breast pumps and equipment, and

- how to obtain a pump from WIC

To identify:

- maternal and infant anatomy that affects an effective and comfortable latch,

- at least 3 signs of a proper latch,

- at least 3 signs of a nutritive suck, and

- at least 3 reasons for a poor latch

To understand:

- maternal and infant issues that

- medical indications for supplementation,

- methods of supplementation, and

- the impact of supplementation on lactation

To identify:

- common maternal BF frustrations and

- common staff frustrations

To explain and use the LOVE counseling technique influence supplementation,

\section{Educational Strategies}

PowerPoint presentation

Participants demonstrate correct SSC positioning using dolls

Participants critique photos of couplets in skin-to-skin positioning for safety

PowerPoint presentation

YouTube video ${ }^{b}$

Participants practice hand expression using breast model

Participants evaluate commercial nursing bras

Lecture

Participants practice with hand and electric pumps

Participants demonstrate setting up, using, and cleaning various styles of pumps

PowerPoint presentation

Participants role-play assisting mothers with BF

Participants analyze photos of couplets for comfortable and effective positioning and latch

Lecture

Quiz game with candy rewards

Participants role-play infant feedings with supplementation tools

Lecture

Participants review scenarios obtained from hospital lactation records and role-play interactions using the LOVE technique
Equipment

Computer and projector

Dolls and blankets

Hospital gowns

Sleeping cot and pillows

Computer and projector

Breastmilk Hand Expression Trainer $^{\mathrm{C}}$

Commercial nursing and hands-free pumping bras

Hand and electric pumps in current use in participating hospitals and City of Dallas WIC

WIC referral forms

Dolls

Soft breast models

Pillows

Commercial infant feeding tools Soft breast models

Dolls

Laminated cards with scenarios

Pocket cards with the LOVE acronym

BF indicates breastfeeding; WIC, Special Supplemental Nutrition Program for Women, Infants and Children.

${ }^{a}$ From Ludington-Hoe and Morgan ${ }^{16}$; ${ }^{b}$ From Morton ${ }^{19}$; ${ }^{\mathrm{C}}$ Limbs \& Things, Ltd; ${ }^{\mathrm{d}}$ Adapted from WIC Value Enhanced Nutrition Assessment: LOVE method of counseling. ${ }^{25}$ 
of Medicine regarding promotion and protecting a woman's milk supply. ${ }^{17-19}$ A commercial rubber breast model (Breastmilk Hands Expression Trainer, Limbs \& Things, Ltd, Bristol, UK) was purchased by WIC for the workshop. Practical information was also provided on how to use and make hands-free pumping bras. ${ }^{20}$ The WIC peer counselors taught the module on the care and use of breast pumps. Since the Texas WIC pump program was established in 1999, peer counselors have distributed pumps and helped mothers to use them. ${ }^{21}$ This workshop used the expertise of WIC peer counselors to educate hospital staff and demonstrate the care they provide in the community. The session on evaluating an effective latch discussed how to obtain a nutritive comfortable latch, evaluate and correct a latch, and score a latch using the LATCHES acronym. ${ }^{22}$ These skills helped staff create appropriate interventions and improve continuity of care. The module for the use of supplemental feedings divided information into 2 categories: maternal issues and infant issues. Tools were explored to provide BF assistance and supplemental feedings. Medical evidence was presented for and against supplemental infant feedings. $^{23,24}$ The most important aspect of the positive messaging module was the LOVE technique: listen, observe, validate, and educate. ${ }^{25}$ When health care workers actively listen, observe a feeding session, and validate the mother's concerns and feelings, trust is developed. The result is that a mother is then open to advice and education.

The creators of the modules presented the information. PowerPoint presentations created by the presenters, lectures, and role-playing were incorporated into the training. In addition, the City of Dallas WIC LCC manager produced a DVD from interviews with patients from the various hospitals and a part of it was viewed. The mothers in the DVD recalled positive and negative hospital and lactation experiences. They expressed thoughts and concerns about how hospital policies and staff influenced their lactation success. The objectives identified in the modules addressed steps 3-5, 6,8 , and 9 of the 10 Steps to Successful BF. Incorporating WIC peer counselors and expanding the role of WIC in the hospitals also addressed step 10 of the BFHI (Table 1$).{ }^{11}$

\section{Validation of Content}

The content and the format were presented to and approved by Baby-Friendly USA. In addition, the program was submitted to the American Nurses Credentialing Center for nursing continuing education credit (CEUs) and 2.6 hours were awarded. The nursing education office from 1 of the hospitals, which is an American Nurses Credentialing Center continuing education provider, agreed to maintain the CEUs for the workshops. For documentation purposes, the workshop was named the WIC Baby-Friendly Clinical Component.

After the workshop was created and CEUs were awarded, member of the administration from each hospital and WIC were approached for approval and all agreed that the workshop would be beneficial. Staff from WIC offered a room at its administration building to conduct the workshops. The hospitals agreed to paid education time for staff and to allow the creators of the trainings paid time to serve as educators. The nursing education departments of the hospitals agreed to track enrollment of the staff that distributed the earned CEUs.

\section{DISCUSSION}

After 6 months of preparation, the BabyFriendly Workshops began. Each work-

$\begin{array}{lc}\text { Table 3. Outline of Typical Workshop } \\ \text { Day } & \\ \text { Activity } & \text { Time, min } \\ \text { Registration-sign-in } & 15 \\ \text { Group assembly: } & 20 \\ \quad \text { introduction and DVD } & \\ \text { Session breakouts } & 20 \\ \quad \text { Station 1 } & 20 \\ \quad \text { Station 2 } & 20 \\ \quad \text { Station 3 } & 20 \\ \text { Break: snacks and } & 20 \\ \quad \text { door prizes } & \\ \quad \text { Station 4 } & 20 \\ \quad \text { Station 5 } & 20 \\ \quad \text { Station 6 } & 20 \\ \text { Group assembly: closing } & 20 \\ \quad \text { remarks and DVD } & \\ \text { Evaluation } & 15 \\ \text { Total time } & 3 \text { h } 30 \text { min }\end{array}$

shop lasted 3.5 hours (Table 3). After signing in, participants met in a large group and viewed the DVD of patient interviews discussed earlier. They were then divided into groups of 10-15 people and simultaneously moved from station to station. After participation in 3 modules, there was a 20 -minute break. Snacks and drinks were provided and there were door prize drawings. Then the groups completed the remaining 3 modules. For the last 20 minutes, they reconvened to the large group and saw more of the patient video and completed the evaluations. The remaining 2 hours of competency verification was completed at their respective facilities. Each hospital designed a process unique to its facility and needs.

\section{Progress}

Initially the workshop was offered 4 times a month and a total of 1000 staff nurses and lactation consultants from the 3 hospitals and WIC were targeted to receive the training. After 9 months, the training frequency decreased to twice a month and finally to once a quarter. After 3 years of activity, 1600 people have participated, including physicians, midwives, dietitians and staff from other area hospitals and clinics. The training has become a standard for new staff orientation. The original team members have been asked to present the content at a variety of workshops and national conferences. It has been presented as a train the trainer unit for several health agencies, who have then created similar programs across the United States. In addition, a Google portfolio was established to share the specifics of the content areas. ${ }^{26}$

One of the participating hospitals achieved the Baby-Friendly Hospital Designation in February of 2015. The other 2 hospitals are in the final phase of the designation process. All of the participating hospitals have reported at least a $10 \%$ increase in their $\mathrm{BF}$ rates.

\section{IMPLICATIONS FOR RESEARCH AND PRACTICE}

Because the workshops are ongoing and have been replicated, several areas for investigation have emerged. First, a prospective study could be designed to evaluate staff knowledge before and 
after the training, paying particular attention to practical application of knowledge learned in the 15-hour didactic education. The purpose would be to see whether the hands-on trainings actually helped solidify the knowledge. Second, the hospitals could track BF rates just before a training and then at 1 and 2 months after the training. By comparing the 3 time intervals, the hospitals would gain insight into (1) the initial impact of the training on staff practices, and (2) how long the effects of training lasted on nursing practice. This could help hospitals plan refresher education to ensure that nurses stayed engaged in the process of applying BF knowledge. Third, because an initial goal of the workshop was to share educational resources, competency verification processes could also be shared. In addition, a consistent message about BF would be provided to patients and the community assisting WIC and the hospitals in improving the lives of women and infants in Dallas.

\section{ACKNOWLEDGMENTS}

The authors would like to thank the City of Dallas WIC, Parkland Health \& Hospital System, and Methodist Health System for their daily commitment to healthy mothers and babies. They would also like to thank them for their support for the lactation skills workshop.

\section{REFERENCES}

1. Hospital Support for BreastfeedingUnited States. and 2009. CDC Vital Signs. Centers for Disease Control. MMWR Morb Mortal Wkly Rpt. 2007;60:1020-1025. http:// www.cdc.gov/vitalsigns. Accessed April 22, 2017.

2. Lutter CK, Chaparro CM. Neonatal period: linking best nutrition practices at birth to optimize maternal and infant health and survival. Food Nutr Bull. 2009; 30:S215-S224. http://search.ebscohost. $\mathrm{com} / \operatorname{login}$.aspx ?direct $=$ true $\& \mathrm{db}=\mathrm{mnh}$ $\& A N=20496614 \&$ site $=$ ehost-live. Accessed April 22, 2017.

3. Owen CG, Martin RM, Whincup PH, et al. Does breastfeeding influence risk of type 2 diabetes in later life? A quantitative analysis of published evidence. Am J Clin Nutr. 2006;84:1043-1054.

4. McCrory C, Murray A. The effect of breastfeeding on neuro-development in infancy. Matern Child Health J. 2013;17:1680-1688.

5. Stuebe A, Rich-Edwards J, Willett W, Manson J, Michels K. Duration of lactation and incidence of type 2 diabetes. JAMA. 2005;294:2601-2610.

6. Bartick MC, Stuebe A, Schwarz EB, Luongo C, Reinhold AG, Foster M. Cost analysis of maternal disease associated with sub-optimal breastfeeding. Obstet Gynecol. 2013;122:111-119.

7. Riley L, Stark A, eds. Guidelines for Perinatal Care. 7th ed. Washington, DC: American Academy of Pediatrics and American College of Obstetricians and Gynecologists; 2012.

8. Eidelman AI, Schandler RJ. Breastfeeding and the use of human milk. Online: American Academy of Pediatrics. 2012; 129:600-603. http://www.pediatrics.org/ cgi/doi/10.1542/peds.2011-3553. Accessed May 24, 2017.

9. Bartick M, Reinhold A. The burden of suboptimal breastfeeding in the United States: a pediatric cost analysis. Pediatrics. 2010;125:e1048-e1056.

10. About Us-Baby-Friendly Hospital Initiative. Baby-Friendly USA. https:// www.babyfriendlyusa.org/about-us/babyfriendly-hospital-initiative. Accessed April 22, 2017.

11. The Ten Steps to Successful Breastfeeding. Baby-Friendly USA. https://www. babyfriendlyusa.org/about-us/baby-friendlyhospital-initiative/the-ten-steps. Accessed April 22, 2017.

12. Getting Started. Baby-Friendly USA. http://www.babyfriendlyusa.org/get-started. Accessed April 22, 2017.

13. The Guidelines \& Evaluation Criteria. Baby-Friendly USA. http://www.baby friendlyusa.org/get-started/the-guidelinesevaluation-criteria. Accessed April 22, 2017.

14. Bergman J, Bergman N. Whose choice? Advocating birthing practices according to baby's biological needs. J Perinat Educ. 2013;22:8-13.

15. Widström A-M, Lilja G, AaltomaaMichalias P, Dahllöf A, Lintula M, Nissen E. Newborn behaviour to locate the breast when skin-to-skin: a possible method for enabling early selfregulation. Acta Paediatr. 2011;100: 79-85.

16. Ludington-Hoe S, Morgan K. Infant assessment and reduction of sudden unexpected postnatal collapse risk during skin-to-skin contact. Newborn and Infant Reviews. 2014;14:29-34.

17. Morton J. Is the use of breast pumps out of hand? Mothers who use "hands-on" techniques see increase in milk production. Am Acad Pediatr News. 2010;30: 14. http://www.aappublications.org/con tent/30/6/14. Accessed May 24, 2017.

18. Morton J, Wong R, Hall J, et al. Combining hand techniques with electric pumping increases the caloric content of milk in mothers of preterm birth. J Perinatol. 2012;32:791-796.

19. Morton J. 15 Minutes of Breastfeeding Help. https://www.youtube.com/watch? $\mathrm{v}=\mathrm{YrBH} 1 \mathrm{KGHNU} 4 \& \mathrm{t}=27 \mathrm{~s}$. Accessed September 14, 2016.

20. Decker C. Hands-free pumping. Kellymom Parenting Breastfeeding. http://kelly mom.com/bf/pumpingmoms/pumping/ hands-free-pumping/. Accessed May 24, 2017.

21. Texas WIC Breast Pump Program. Texas Department of State Health Services. https://www.dshs.texas.gov/wichd/bf/bf about.shtm\#AboutProgram. Accessed April 22, 2017.

22. Walker M. Breastfeeding Management for Clinicians: Using the Evidence. New York, NY: Jones \& Bartlett Publishers; 2010.

23. Lawrence RA, Lawrence R. Breastfeeding: A Guide for the Medical Professional. 6th ed. St Louis, MO: Mosby; 2005.

24. Academy of Breastfeeding Medicine Protocol Committee. Hospital Guidelines for the Use of Supplementary Feedings in the Healthy Term Breastfed Neonate. Breastfeed Med. 2009;4: 175-182.

25. WIC Value Enhanced Nutrition Assessment, WIC Staff News. Texas Department of State Health Services. https:// www.dshs.texas.gov/wichd/nut/vena_ newsletter/Vena_Articles/LoveMethod.sht. Accessed April 22, 2017.

26. Stepping Up Your Baby Friendly Game: Community Collaborative for Hospital Staff Education Google portfolio. https:// sites.google.com/site/steppingupyourbaby friendlygame. Accessed April 22, 2017. 


\section{CONFLICT OF INTEREST}

The authors have not stated any conflicts of interest. 